PSI COLOGI A SOCI AL

\title{
Sobrepeso e obesidade na mídia impressa: uma análise retrospectiva na revista Veja
}

\section{Overweight and obesity in the press: a retrospective analysis of Veja magazine}

\section{El sobrepeso y la obesidad en la prensa: un análisis retrospectivo de la revista Veja}

\author{
Ana Maria J usto* \\ Universidade Federal do Espírito Santo - UFES, Vitória, Espírito Santo, Brasil
}

\author{
Brigido Vizeu Camargo** \\ Universidade Federal de Santa Catarina - UFSC, Florianópolis, Santa Catarina, \\ Brasil
}

\begin{abstract}
RESUMO
O estudo teve como objetivo investigar as representações sociais do excesso de peso corporal difundidas em uma revista de circulação nacional. No período de 1968 a 2012 foram identificadas 198 reportagens e 21 manchetes de capa relacionadas ao sobrepeso ou obesidade. Todas as reportagens internas foram submetidas à análise categorial múltipla e as de capa foram organizadas em um único corpus, submetido a uma Classificação Hierárquica Descendente, com o auxílio do software IRAMUTEQ. Embora tenha ganhado significativamente maior espaço na revista a partir dos anos 2000, quando a obesidade passa gradativamente de um objeto da ciência a um assunto do cotidiano, a forma de abordar o corpo com excesso de peso mostra-se relativamente estável desde a década de 1960. O sobrepeso é necessariamente associado ao emagrecimento e a gordura aparece como um elemento a ser eliminado. Grande parte do conteúdo analisado refere-se à difusão de conhecimentos técnicos e descobertas científicas diretamente ligadas ao emagrecimento, sendo a alimentação um assunto em destaque. São mencionadas as dificuldades enfrentadas pelas pessoas com excesso de peso, na medida em que o emagrecimento é necessário e exige uma rotina regrada, muitas vezes na contramão das atividades sociais prazerosas.
\end{abstract}

Palavras-chave: representações sociais, mídia, obesidade, sobrepeso.

\section{ABSTRACT}

The study aimed to investigate the social representations of excess body weight spread in a national magazine. During the period from 1968 to 2012, we found 198 internal reports and 21 cover reports related to overweight or obesity. All internal reports were submitted to multiple categorical analysis and cover reports were organized into a single corpus, submitted to a Descending Hierarchical Classification, by the software IRAMUTEQ. Although it has gained significantly more space in the journal since the 2000s, when obesity gradually shifts from an object of science to a matter of everyday 
life, the way of approaching the excess weight body has been relatively stable since the 1960s. It was observed that overweight is necessarily associated with slimming and fat appears as an element to be deleted. Much of the content analysis refers to the dissemination of technical knowledge and scientific discoveries directly related to weight loss, with nutrition as a hot topic. They are mentioned the difficulties faced by people with overweight to the extent that weight loss is necessary and requires a regimented routine, often against the pleasurable social activities.

Keywords: social representations, media, obesity, overweight.

\section{RESUMEN}

El objetivo del estudio fue investigar las representaciones sociales de exceso de peso repartidas en una revista nacional. En el período de1968 a 2012, identificamos 198 artículos y 21 reportajes de portada relacionados con el sobrepeso o la obesidad. Todos los artículos internos fueron sometidos a un análisis por categorías y les reportajes de portada se agruparon en un único corpus, sometido a una clasificación jerárquica descendente, con la ayuda de software IRAMUTEQ. A pesar de que ha ganado significativamente más espacio en la revista de la década de 2000, cuando la obesidad se convierte poco a poco un objeto de la ciencia a un objeto cotidiano, la forma de abordar el cuerpo con exceso de peso muestra relativamente estable desde la década de 1960. Se observó que el sobrepeso se asocia con el adelgazamiento y la grasa aparece como un elemento que se desea eliminar. Gran parte del contenido analizado se refiere a la difusión de los conocimientos científicos y técnicos relacionados con la pérdida de peso, donde la comida era excepcional. Se mencionan las dificultades que enfrentan las personas con sobrepeso en la medida en que la pérdida de peso es necesaria y requiere una rutina reglamentada, en contra de las actividades sociales deleitables.

Palabras clave: representaciones sociales, medio, obesidad, sobrepeso.

\section{I ntrodução}

O Brasil, que poucas décadas atrás investia em campanhas de combate à fome, hoje desenvolve programas que visam controlar o aumento de peso excessivo da população. O número de pessoas obesas tem aumentado significativamente e, segundo dados da Organização Mundial da Saúde (OMS, 2015), dobrou no mundo, desde a década de 1980. Atualmente, cerca da metade da população brasileira encontra-se com excesso de peso.

A saúde ocupa um espaço cada vez mais importante nas sociedades, que reiteram a necessidade de aderir a comportamentos saudáveis, visando a diminuição do risco de doenças. Mais do que um objeto da medicina, é um fenômeno social (Fischer, 2002), de modo que não se pode considerá-la como um valor autônomo (Adam \& Herzlich, 2001), mas como uma construção social. Isso aponta à necessidade de se compreender os fenômenos de saúde dentro da complexa realidade social na qual eles se manifestam (Apostolidis, 2006).

Ao extrapolar a esfera individual e adentrar o plano sociocultural, os aspectos ligados ao sobrepeso e obesidade passam a adquirir 
nuances e sentidos que ultrapassam os limites do corpo físico e das vontades individuais, evidenciando suas dimensões sociais, partilhadas. O social, mais do que determinar efeitos sobre a saúde, fornece um sistema de interpretação do mundo e, por conseguinte, das doenças e dos riscos relativos à saúde (Morin \& Apostolidis, 2002). Nesse sentido, olhar das representações sociais (RS) propõe uma leitura multiníveis que permite analisar sistemas de percepção e de ação mobilizados na construção da realidade social (Apostolidis, 2006).

O corpo humano, além de um organismo natural, conforme representado pela biologia moderna (Separavich \& Canesqui, 2010), constitui-se a partir de representações individuais e sociais. Essas representações se manifestam na forma como cada um o usa, adoece, percebe, altera, degrada e o transforma, refletindo também o momento histórico, econômico e social de um grupo (Andrieu, 2006). Ao mesmo tempo em que se trata de um dos objetos mais privados que possuímos, o corpo é o meio pelo qual se torna possível nossa interação social (Alferes, 1987). Nessa relação dialética, são construídas as RS ligadas ao corpo por meio de processos que consideram ao mesmo tempo experiências individuais e sociais (Jodelet, 1994). Segundo a autora, RS podem ser manifestas pelo que é dito e pelas ações relativas ao corpo, por seus movimentos, suas expressões, bem como pelo papel atribuído à aparência nas relações sociais.

Considera-se que as RS assumem um papel importante na elaboração de maneiras coletivas de ver e viver o corpo, difundindo modelos de pensamento e de comportamento a ele relacionados (J odelet, 1994). Portanto, pretende-se abordar os aspectos psicossociais ligados ao corpo humano, mais especificamente no que tange ao excesso de peso, a partir da abordagem da teoria das representações sociais (TRS).

A TRS explica as atividades da sociedade contemporânea ligadas a processos de comunicação e informação (Jodelet, 2001). Segundo Vala \& Castro (2013), esta consiste numa teoria científica sobre os processos por meio dos quais os indivíduos em interação constroem explicações acerca dos objetos sociais. As RS são uma forma de conhecimento social, uma forma de interpretar e pensar a realidade cotidiana (J odelet, 1984). Esse conhecimento prático, dá um sentido aos eventos cotidianos, fazendo parte da construção social da realidade (Berger \& Luckmann, 2011). As RS permitem-nos conhecer as características da realidade coletiva, envolvendo saberes que orientam as ações dos indivíduos no seu cotidiano (Moscovici, 1981).

Como questão central à TRS estão os processos de transformação do conhecimento científico em conhecimento do senso comum, assim como o movimento inverso, no qual o saber de senso comum fornece elementos para a produção de conhecimento científico (Moscovici, 
1981, 2012). O universo consensual é aquele em que o conhecimento é compartilhado livremente. No universo reificado (científico), por sua vez, existe um sistema de papéis e hierarquias, sendo a participação determinada pela qualificação do indivíduo. As RS emergem na interação entre estes dois universos, uma vez que veiculam os conhecimentos científicos e os articulam com a cultura e os saberes populares, tornando tal conhecimento acessível à população que se insere na vida cotidiana (Chaves \& Silva, 2011).

Os sistemas sociais se constituem com base na comunicação, de modo que o processo de evolução social é dependente dos processos comunicativos (Rüdiger, 2011). Nesse sentido, a comunicação social alavanca a difusão de conhecimentos, amplia as formas de pensamento social e revela-se de importância marcante na disseminação de crenças, valores e RS (Moscovici, 1981; Rouquette, 1986). Por comunicação social, entende-se o conjunto de técnicas de difusão coletiva que permitem chegar a um grande público, que se configura numa transmissão quantitativamente relevante de informações semelhantes a indivíduos ou grupos numerosos e heterogêneos (Fischer, 1996).

A presença dos meios de comunicação social torna-se cada vez mais intensa no modo de vida contemporâneo e esses meios oferecem um caminho, além das relações face a face, que permite às RS circularem nos grupos e na sociedade (Camargo, 2003). As comunicações de massa são consideradas um terreno propício ao pensamento social, onde as elaborações cognitivas participam do fundo de saberes comuns e das trocas entre os grupos (Rouquette, 2005). A mídia veicula conteúdos culturais, produzindo o que podemos chamar de cultura de massas: um conjunto de conhecimentos, valores, estereótipos e mitos que passam a circular no cenário social. A existência de crenças, representações e modelos culturais se manifesta no conteúdo da comunicação em massa, bem como na forma como se dá o tratamento e a elaboração secundária dos conteúdos, realizada pelos grupos (Rouquette,1986).

As mensagens midiáticas são reflexo daquele que emite e também do meio que as recebe, ou seja, são a expressão de uma cultura, ao mesmo tempo em que consistem num instrumento que a modela (Kientz, 1973). A forma como os indivíduos hierarquizam os eventos ou temas públicos tende a ser semelhante à avaliação dada pela mídia (Wolf, 1999). Assim, pode-se dizer que as representações que circulam na sociedade guardam relação com a natureza das informações e das imagens que circulam na mídia (Dayan, 2003).

Sabe-se que as RS são de melhor maneira exploradas no discurso público. Os fenômenos que se mostram um problema social aumentam a tensão e por isso, tornam-se assuntos de debate (Marková, 2006). Portanto, considera-se que a análise do conteúdo midiático pode contribuir à compreensão de crenças, representações 
e valores atrelados aos temas relevantes do cotidiano, na medida em que revelam, a partir de dados naturais, as ideias compartilhadas por uma cultura dentro de um determinado recorte temporal. Desse modo, o objetivo do presente estudo é descrever as RS relativas ao excesso de peso corporal que circularam na mídia ao longo das últimas décadas, já que esta é uma importante fonte de informação para a adoção de RS na sociedade contemporânea (J odelet, 2001).

\section{Método}

Trata-se de um estudo documental, retrospectivo, de caráter exploratório e descritivo. Optou-se por analisar o conteúdo da revista Veja, uma revista semanal de informação que aborda temas da atualidade brasileira e mundial. Foi a primeira do gênero a circular no Brasil e é considerada a revista mais lida no país (Silva \& Gonzales, 2008). Seu primeiro exemplar data de 11 de setembro de 1968 e quando surgiu, visava a integração de um país continental por meio da notícia (Villalta, 2002). Esta revista, sobretudo nas últimas décadas, reflete os principais tópicos agendados por outros meios importantes de informação, como a televisão, o rádio e outras revistas. Sua periodicidade é semanal, e tem cerca de 10.448.135 leitores, equilibrados quanto ao gênero. Ela é voltada para o público adulto e abrange, sobretudo, as classes média e alta (EGM, 2012).

Os dados para o estudo foram coletados a partir do Acervo Virtual disponível na internet com acesso gratuito, relativo às publicações do período de setembro de 1968 a dezembro de 2012, e envolveu duas etapas: (1) Reportagens Internas: foram selecionados, com auxílio da ferramenta de busca da revista, os artigos que tratavam especificamente de assuntos ligados ao excesso de peso corporal. (2) Reportagens de Capa: foi analisado o conteúdo das capas das edições da revista e selecionadas todas aquelas que apresentaram conteúdo associado ao excesso de peso corporal. Os arquivos relativos às capas foram transformados em documentos textuais e reunidos em um único arquivo de texto, compondo o corpus "Reportagens de Capa".

O material referente às reportagens internas foi submetido a uma análise de conteúdo por categorias múltiplas, tanto do texto quanto das ilustrações dos artigos (Banks, 2008). A análise categorial desmembra o conteúdo total e agrupa-os por categorias que reúnem grupos de elementos com características comuns, a partir de uma classificação (Bardin, 2009).

O corpus "Reportagens de Capa" foi submetido a uma Classificação Hierárquica Descendente (CHD) com o auxilio do software IRAMUTEQ - Interface de R pour les Analyses Multidimensionnelles de Textes et de Questionnaires (Camargo \& Justo, 2013). A CHD indica contextos 
lexicais, associados ou não a variáveis descritivas dos produtores deste material, que, de acordo com Veloz, Nascimento-Schulze e Camargo (1999), podem ser considerados como aspectos de uma RS, ou mesmo como indicadores de diferentes RS.

\section{Resultados}

Entre 1968 e 2012 foram publicadas 2.031 edições da revista Veja. E neste período identificou-se 198 reportagens envolvendo a temática do excesso de peso corporal, das quais 21 foram reportagens de capa. O número de reportagens sobre esse assunto na revista foi crescente ao longo do tempo. Se até o ano de 1996 havia menos de cinco reportagens por ano, deste ano em diante o número aumentou consideravelmente, chegando a 20 publicações nos anos 2005 e 2009, conforme se pode observar na Figura 1.

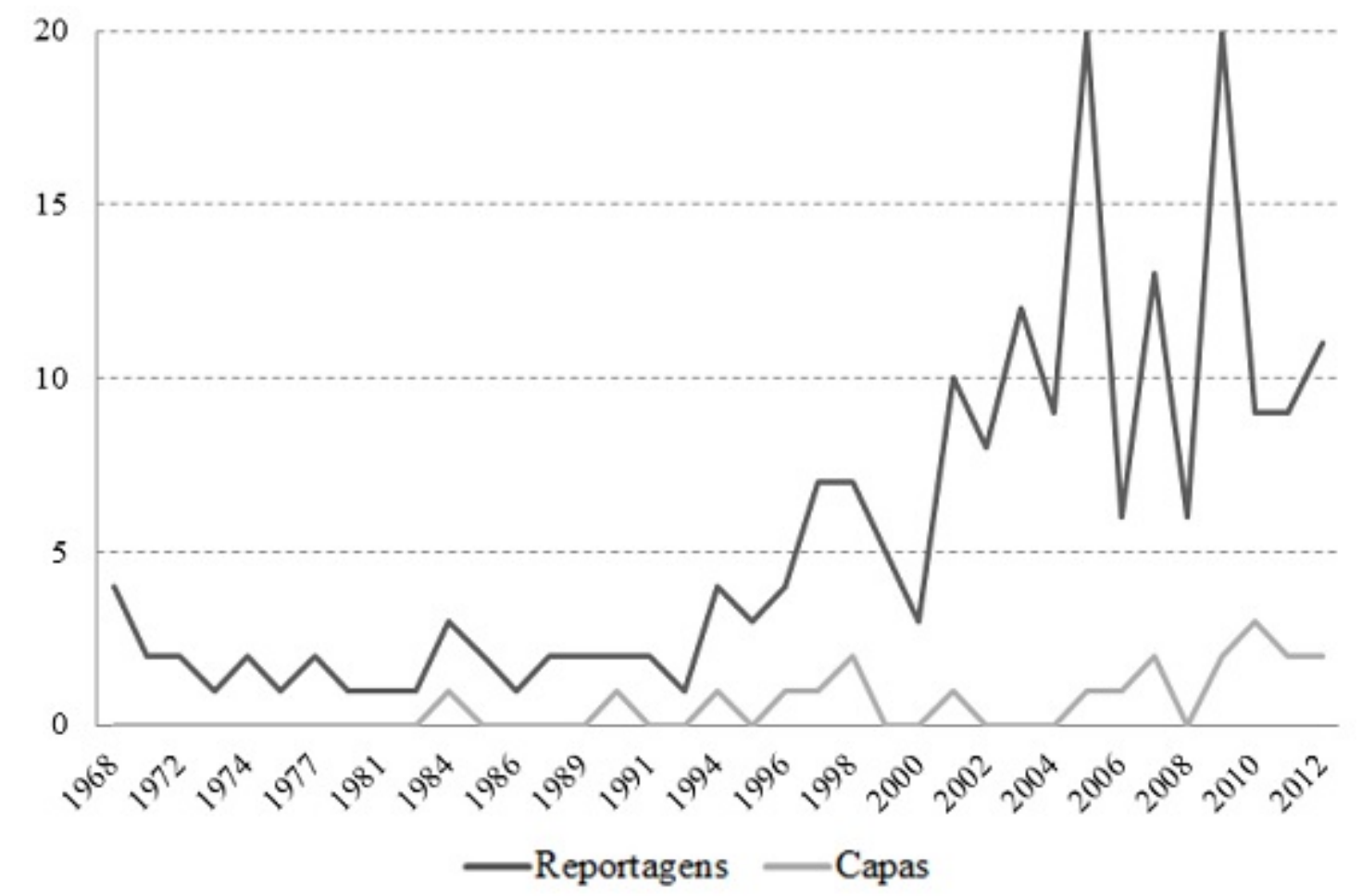

Figura 1. Número de reportagens e capas publicadas na revista sobre o assunto, por ano.

As 198 reportagens internas foram submetidas a uma análise de conteúdo com categorias múltiplas. No total, foram analisadas 511 páginas de conteúdo, sendo que as reportagens variaram entre menos de uma página inteira, até 13 páginas dedicadas ao tema. Em média as reportagens tiveram de duas a três páginas ( $D P=2,5$ páginas). A maior parte delas trazia novidades (notícias) ligadas ao 
tema (71\%) e cerca da metade (51\%) incluiu algum tipo de divulgação científica; $26 \%$ traziam opiniões - de pessoas famosas ou comuns, e $21 \%$ apresentavam prescrições de comportamentos ligados ao controle de peso.

Ao longo dos 44 anos analisados destacam-se as reportagens que abordam o excesso de peso associando-o diretamente com práticas de controle de peso $(55,6 \%)$. Por práticas de controle de peso, entendem-se as ações cotidianas que visam à redução ou manutenção do peso (Justo, 2016). A tabela 1 especifica os temas norteadores das reportagens e suas respectivas frequências, agrupados em categorias.

Tabela 1: Temas predominantes nas reportagens internas

\begin{tabular}{|c|c|c|c|c|c|c|}
\hline Tema & Freq. & $\%$ & Grande Tema & Freq. & $\%$ & \multirow{24}{*}{$\begin{array}{c}\text { Práticas de } \\
\text { Controle de Peso } \\
\text { Freq. }=110 ; 55,6 \%\end{array}$} \\
\hline Alimentaçào saudável & 16 & 8,1 & \multirow{5}{*}{ Alimentação } & \multirow{5}{*}{35} & \multirow{5}{*}{17,7} & \\
\hline Açúcar/Adoçante & 7 & 3,5 & & & & \\
\hline Alimentos que engordam & 6 & 3,0 & & & & \\
\hline Nutrição Infantil & 4 & 2,0 & & & & \\
\hline Alimentação errada & 3 & 1,5 & & & & \\
\hline Exercício & 4 & 2,0 & Exercício & 4 & 2 & \\
\hline Dieta para emagrecer & 28 & 14,1 & \multirow{7}{*}{ Emagrecimento } & \multirow{7}{*}{71} & \multirow{7}{*}{35,9} & \\
\hline Medicamento para emagrecer & 22 & 11,1 & & & & \\
\hline Cirurgia para reduzir peso & 7 & 3,5 & & & & \\
\hline Tratamento da obesidade & 6 & 3,0 & & & & \\
\hline Indústria do emagrecimento & 4 & 2,0 & & & & \\
\hline Celebridades perdem peso & 3 & 1,5 & & & & \\
\hline Suplementos emagrecedores & 2 & 1,0 & & & & \\
\hline Epidemia & 26 & 13,1 & \multirow{2}{*}{ Sociedade Obesa } & \multirow{2}{*}{39} & \multirow{2}{*}{19,7} & \\
\hline Obesidade Infantil & 12 & 6,1 & & & & \\
\hline Riscos para a Saúde & 17 & 8,6 & \multirow{3}{*}{ Saúde } & \multirow{3}{*}{23} & \multirow{3}{*}{11,6} & \\
\hline Ser gordo não prejudica a saúde & 5 & 2,5 & & & & \\
\hline Obesidade Mórbida & 2 & 1,0 & & & & \\
\hline Metabolismo & 10 & 5,1 & \multirow[b]{2}{*}{ Fatores Agravantes } & \multirow{2}{*}{14} & \multirow{2}{*}{7,1} & \\
\hline Influência genética & 2 & 1,0 & & & & \\
\hline Aceitação & 7 & 3,5 & \multirow{3}{*}{ Padrões Sociais } & \multirow{3}{*}{12} & \multirow{3}{*}{6,1} & \\
\hline Beleza & 3 & 1,5 & & & & \\
\hline Preconceito com os gordos & 2 & 1,0 & & & & \\
\hline
\end{tabular}

O "emagrecimento" foi tema predominante, abordado por meio dos mais diversos recursos: da dieta restritiva, passando pelo uso de medicamentos, até intervenções mais invasivas, como cirurgias plásticas e de redução de estômago. Em segundo lugar destacam-se as ideias de "sociedade obesa" e a de "alimentação". Artigos que ressaltam o excesso de peso como um problema da sociedade, tratam o assunto como uma epidemia que preocupa. A ideia de "alimentação" é desenvolvida com base numa dicotomia ente aquela saudável e a inadequada. Os demais temas apresentaram-se de 
forma mais discreta, como o da saúde, o dos fatores agravantes e o dos padrões sociais. Há pequena incidência de reportagens que abordam a prática de exercícios físicos.

Além das práticas de controle de peso serem temática principal de mais da metade dos artigos, constatou-se que $85 \%$ deles as mencionaram em seu conteúdo. Parece difícil pensar no excesso de peso corporal sem considerar as intervenções possíveis a respeito dessa condição. Dentre elas, a alimentação ocupa o maior espaço, em $76 \%$ das reportagens, enquanto os exercícios físicos em $27 \%$, medicamentos em $18 \%$ e cirurgias em $7 \%$.

Quanto ao informante, a maioria das reportagens são assinadas por um jornalista, responsável pela maior parte do artigo. Entretanto, $53 \%$ das reportagens têm cientistas ou estudos científicos como referência; $48 \%$ apresentam a fala de profissionais de saúde; $25 \%$ trazem relatos de pessoas comuns e $15 \%$ de "celebridades" nacionais ou internacionais.

Quase todas as reportagens (91\%) apresentaram imagens ilustrativas do seu conteúdo textual. Em $77 \%$ das reportagens aparecem imagens de pessoas e predominam adultos (66\%), brancos (74\%) sendo o corpo evidenciado na maioria delas (72\%). Há relativo equilíbrio na ocorrência de homens e mulheres e um leve predomínio da ocorrência de pessoas magras (55\%). As práticas de controle de peso também se mostram evidentes nas ilustrações das reportagens, uma vez que $54 \%$ dessas possuem pelo menos uma imagem relativa a alguma prática e, mais uma vez, a alimentação é a mais saliente (45\% das reportagens). Quase metade das reportagens apresentavam imagens de alimentos ou de pessoas se alimentando. O exercício físico apareceu nas imagens de $15 \%$ das reportagens e os medicamentos em apenas 3,5\%.

A primeira vez que a temática estudada apareceu como reportagem de capa foi no ano de 1984, edição no. 850: “A popularidade do regime: a arte de comer sem remorso", anunciando sete páginas na sessão Comportamento, que abordavam a preocupação dos brasileiros com a silhueta e a constante busca pelo emagrecimento por meio de métodos diversos. Durante a década de 1990 foram publicadas seis reportagens de capa; entre 2000 e 2009 foram sete, assim como de 2010 a 2012. O número de capas dos últimos três anos é equivalente ao publicado nas décadas anteriores, ilustrando o realce que a temática do excesso e controle do peso adquiriu na agenda social brasileira nos últimos anos analisados.

As 21 reportagens do período de 1984 a 2012, as quais abordavam assuntos relativos ao excesso de peso corporal compuseram o corpus "Reportagens de Capa" que foi submetido a uma análise lexicográfica do tipo CHD. Esses 21 textos iniciais desdobraram-se em 2.466 segmentos de texto (ST). Destes, 2.181 (88,44\% do total) foram retidos na CHD realizada com o auxílio do software IRAMUTEQ. Após 
a lematização, foram identificadas 11.456 formas distintas, que ocorreram 87.498 vezes $(F M=7,64)$. A CHD dividiu o corpus em seis classes, as quais se encontram ilustradas no dendrograma da Figura 2 , que apresenta as palavras mais significativas de cada classe, seguidas pela sua ocorrência na classe e associação com a mesma (por teste de qui-quadrado).

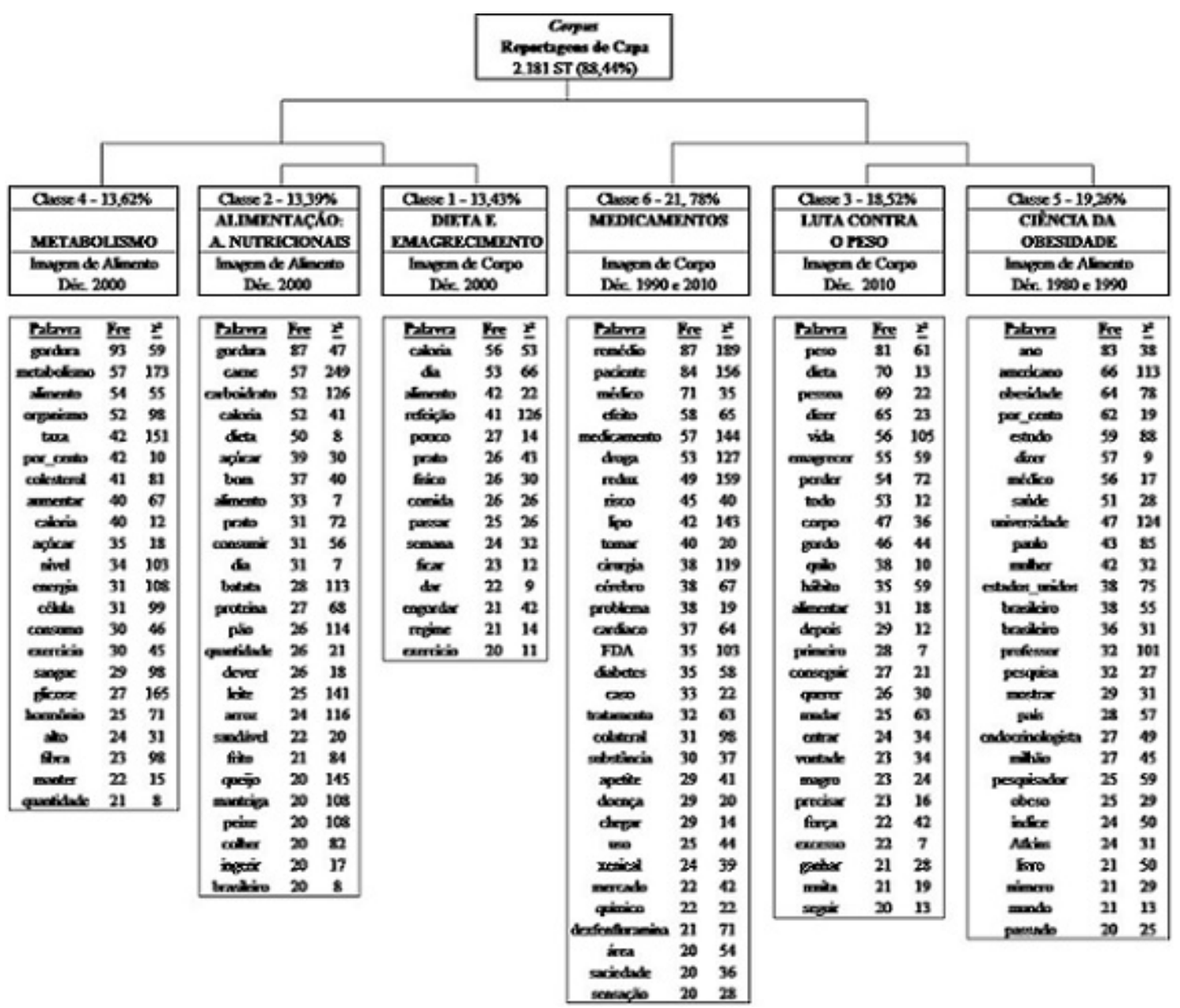

Figura 2. Dendrograma da CHD do corpus "Reportagens de Capa".

Na primeira partição, o corpus dividiu-se em dois sub-corpora, em que os aspectos alimentares e metabólicos (classes 4,2 e 1) diferenciaram-se das demais classes (6,3 e 5), as quais abordaram o uso de medicamentos, a luta contra o peso e as pesquisas científicas. A segunda partição deu origem à classe "Metabolismo". A terceira partição originou a classe "Medicamentos". A quarta partição diferenciou as classes 1 e 2 entre si e, por fim, a quinta partição diferenciou as classes 3 e 5 .

A classe 4, "Metabolismo", representa 13,62\% dos ST classificados, esteve associada à década de 2000 a 2009. A palavra de maior frequência na classe é gordura, seguida por metabolismo, alimento, organismo e demais elementos que se encontram na figura 2 . 0 
metabolismo tem papel central e a gordura é abordada tecnicamente enquanto elemento fundamental ao seu funcionamento. A Gordura é essencial no fornecimento de energia na absorção das vitaminas a d e e $k$, no metabolismo hormonal, no controle do colesterol, no funcionamento intestinal e contra o ressecamento da pele e dos cabelos (Edição 1569, Ano 1998). Por outro lado, dependendo da localização e quantidade, pode ser prejudicial ao organismo. A gordura visceral produz uma série de compostos todos prejudiciais ao organismo direta ou indiretamente eles aumentam a quantidade de açúcar no sangue impedem a ação do hormônio insulina (Edição 1971, Ano 2006).

O funcionamento metabólico abrange a ingestão de calorias e nutrientes, e também a produção e consumo de energia; o que se dá por meio de determinado ritmo metabólico, que pode ser alterado com exercícios e alimentação. Também são abordados os riscos para a saúde de alguns excessos (principalmente açúcar e gordura) no sangue. O vocabulário dessa classe é técnico e objetivo, trazendo informações científicas acerca do funcionamento metabólico e suas relações com a gordura corporal.

As classes 1 e 2, que juntas, correspondem a $27 \%$ do corpus analisado, também estiveram associadas à década de 2000 a 2009 e ambas abordam a temática da alimentação. A classe 2, "Alimentação: aspectos nutricionais", refere principalmente a composição nutricional e características funcionais dos alimentos, que envolvem sobretudo: gorduras, carboidratos e proteínas. Profissionais e cientistas orientam sobre o uso e a quantidade adequada para o consumo dos alimentos nas dietas, visando uma alimentação equilibrada e saudável. A gordura do bem: a ciência da nutrição passa por uma reviravolta sem precedentes ao afrouxar as restrições ao consumo de queijos, carnes e manteiga; antes tidos como vilões a virada das recomendações (Edição 2275, Ano 2012). Há a menção também às rotinas alimentares de algumas "celebridades" da época, tais como Vera Fisher, Carla Perez e Fause Hasten (estilista), como exemplos de alimentação adequada.

Já a classe 1, "Dieta e emagrecimento", aborda a alimentação tendo o emagrecimento como elemento fundamental. $\mathrm{O}$ ato de comer é um comportamento que pode levar diretamente ao ganho ou perda de peso. O vocabulário dessa classe trata das dietas e comportamentos alimentares voltados diretamente ao emagrecimento, abordando fatores que auxiliam e que dificultam o sucesso do mesmo. O mais importante é ter uma boa ideia do que se come e de quanto se come, se os alimentos são muito ou pouco calóricos. Quem tem esse costume, quando exagera, automaticamente come menos na próxima refeição (Edição 2152, Ano 2010). Trata-se de um conteúdo informativo, e parte dessa classe apresenta relatos de experiência, tanto de famosos quanto de pessoas comuns, acerca de dieta e 
emagrecimento. A advogada Andréa Santoro, 28, anos sabe do que Tânia está falando. Passo o dia comendo certinho, levo uma lancheira para o trabalho com cenourinhas, frutas, iogurte (Edição 2114, Ano 2009).

A distinção entre os conteúdos dessas duas classes ao abordar a alimentação fica evidente nas imagens presentes nas capas. Enquanto a classe 2 está associada a imagens de alimentos, o que evidencia o seu foco nas propriedades dos mesmos, a classe 1 associou-se a figuras de corpos magros e femininos, onde o foco é o emagrecimento.

A classe 6, "Medicamentos" representa $21,78 \%$ dos ST retidos na análise e aborda o emagrecimento com auxílio de remédios próprios para este fim. Está associada à década de 1990 e às publicações a partir de 2010. Traz as diferentes substâncias usadas ao longo do tempo, sua evolução, suas ações no corpo, e efeitos colaterais, salientando a necessidade de acompanhamento médico e os riscos envolvidos no uso dos medicamentos. Uma parte do conteúdo é relativa à regulamentação dos medicamentos, sua avaliação por pesquisas científicas e aprovação ou não pelos governos norte americano e/ou brasileiro. Na semana passada a agência nacional de vigilância sanitária - ANVISA - órgão do ministério da saúde anunciou a intenção de banir do mercado os principais remédios para emagrecer que agem sobre o sistema nervoso central, os anorexígenos: sibutramina femproporexan fepramona e mazindol (Edição 2233, Ano 2011).

Nas manchetes de capa de que foram associadas à classe "Medicamentos" destaca-se o combate à gordura. A foto de um corpo magro contrasta com aquela de corpo obeso. Outras ilustrações mostram alimentos gordurosos, que podem ser ingeridos sem medo, uma vez que a medicação reduz a absorção da gordura pelo organismo. Nesse sentido, os medicamentos surgem como uma solução rápida, uma forma de "driblar" o metabolismo e manter o corpo magro.

A classe 3, "Luta contra o peso", representa $18,52 \%$ do total de ST e esteve associada ao período a partir de 2010 e seu conteúdo girou em torno do desafio de emagrecer vivenciado pelas pessoas. Essa classe é menos técnica e traz as experiências de vida. Em geral, o emagrecimento é descrito como um processo difícil e demorado, que requer mudança de hábitos, metas claras, dedicação, disciplina e força de vontade. Dito assim, parece fácil. Quem já fez dieta uma vez na vida sabe que existem forças engordativas, como define Alfredo Halpern, jogando contra o peso que se deseja atingir (Edição 2000, Ano 2007). O conteúdo é abordado por meio de informações fornecidas por médicos, assim como por depoimentos ou exemplos de pessoas que lutam ou lutaram com o peso. Aos 36 anos o ex-jogador é um exemplo acabado de como os fatores externos tanto os da vida 
pessoal como os da carreira podem minar ou fortalecer a disposição para alcançar determinados objetivos no caso dele a manutenção do peso ideal (Edição 2289, Ano 2012). Diferentemente das outras classes, onde o foco eram as práticas relativas ao emagrecimento, aqui a atenção volta-se ao corpo em si, e como as pessoas lidam com sua forma corporal, na maior parte das vezes buscando perder peso, seja para cuidar da saúde, ou por imposição social.

Por fim, a classe 5, "Ciência da Obesidade", com 19,26\% dos ST e associada às décadas de 1980 e 1990. Esta é a única a abordar diretamente a obesidade em si, considerada como um fenômeno que cresce tanto no Brasil quanto no mundo e acomete adultos e crianças, o que se configura num problema de saúde pública, uma vez que é considerada uma doença. Temos visto casos de crianças que apresentam hipertensão e índice de colesterol elevado, conta a endocrinologista Cláudia Cozer, diretora da Associação Brasileira para - Estudo da Obesidade e da Síndrome Metabólica (Edição 2171, Ano 2010). A classe apresenta, sobretudo, as pesquisas nacionais e internacionais que envolvem a problemática da obesidade, no que se refere tanto aos fatores que contribuem para ela, quanto às novas possibilidades de tratamento. Ganham voz os médicos e as universidades brasileiras e norte-americanas. Nessa classe aparecem as pessoas obesas, como objeto do saber científico, caracterizadas por termos técnicos.

Os resultados da CHD corroboram os dados da análise de conteúdo das reportagens internas da revista. As representações difundidas pela mídia evidenciam o sobrepeso e a obesidade como características impróprias, não saudáveis e que devem ser modificadas. A maior parte do conteúdo é informativo e predominam discursos técnicos e científicos que fundamentam esta ideia e que viabilizam o emagrecimento, o que reflete numa negação ao excesso de peso. As imagens que acompanham às manchetes, quase que invariavelmente, mostram alimentos apetitosos ou corpos femininos magros e "em forma". Dentre as 21 capas, apenas 3 exibiam corpos com excesso de peso, sendo um deles uma caricatura.

\section{Discussão}

Em um processo dinâmico, alguns dos fenômenos passam a se configurar como problema social e consequentemente, ganham visibilidade nos meios de comunicação de massa (Marková, 2006). Com relação ao excesso de peso, verificou-se que ao mesmo tempo em que esse passou a afetar mais intensamente a população, em termos epidemiológicos, a partir dos anos 2000 (Brasil, 2011), também ganhou destaque na mídia impressa analisada, que veio a 
incluí-lo sistematicamente na lista dos assuntos sobre os quais é necessário ter uma opinião e discutir (Shaw, 1979).

Raramente a atenção pública fica voltada por longos períodos a um mesmo assunto, pois a mídia apresenta ciclos de interesse em relação aos fenômenos sociais (Downs, 1972). Parte deste ciclo foi identificado na revista Veja em relação ao excesso de peso, fenômeno que começou a ganhar destaque a partir dos anos 2000, tendo um primeiro pico em 2005, poucos anos após a divulgação de importantes resultados do Ministério da Saúde em relação à situação ponderal da população, quando configurou-se a fase alarmante do problema. Em seguida, mesmo permaneceu em fase de manutenção até 2012 , final do período analisado.

Ao considerar a análise retrospectiva ao longo de 40 anos, não se pode deixar de considerar a grande transição nutricional pela qual o Brasil passou nas últimas décadas. O país tinha a desnutrição como uma prioritária preocupação de saúde pública até a década de 1980, sendo que a partir da década de 1990 o excesso de peso passa a prevalecer e ganham espaço as campanhas de prevenção e combate à obesidade (Souza, 2010). As políticas de saúde relativas ao excesso de peso da população ascenderam a partir de 1990, ganhando força a partir do ano 2000, quando legislação e outras políticas públicas no Brasil e no mundo passam a atentar ao excesso de peso da população (Arruda \& Arruda, 2007).

Ao longo das quatro décadas verifica-se uma representação do corpo relativamente estável. Com ênfase pragmática, são destacadas as práticas que abordam $\mathrm{O}$ emagrecimento em todas as décadas. Todavia a A CHD apresentou a associação das classes a diferentes períodos, sugerindo algumas mudanças no conteúdo publicado ao longo do tempo. A obesidade como fenômeno de saúde é característica dos anos 1980-1990, época em que a ciência começa a constatá-la como um problema que atinge o povo brasileiro. Tanto que, na década de 1990 entram em pauta os medicamentos para controle de peso. A partir dos anos 2000, o conteúdo publicado enfatiza o metabolismo e a alimentação com seus impactos no controle ponderal. Mais recentemente, de 2010 a 2012, os medicamentos voltam a ser abordados e há espaço para relatos de experiências relativas à "luta contra o peso". O conteúdo envolve relatos de experiências pessoais que priorizam a responsabilização individual pela silhueta corporal. Ao mesmo tempo, ilustram o processo de difusão do conhecimento científicos sobre o tema da obesidade, que se mostra cada vez mais presente na "agenda" social, nas políticas públicas de saúde, e nos discursos cotidianos, misturando ciência e senso comum, em um processo que característico às RS (Moscovici, 2012).

No processo de difusão do conhecimento científico, este é modificado e popularizado, de modo a tornar-se compreensível às pessoas 
(Moscovici 1984). Nesse curso, a mídia tem lugar fundamental, pois além de oferecer um caminho que permite às representações circularem nos grupos e na sociedade (Camargo, 2003), configura-se como uma forma de passagem do conhecimento de um universo reificado, para o universo consensual, construindo os pensamentos de senso comum a partir de um processo de transformação do conhecimento, que se insere na cultura local. Como âncoras que orientam a construção de representações, os sistemas de comunicação geram diferentes modalidades de objetivação das ideias e dos fenômenos sociais (Ordaz \& Vala, 1997).

Este processo ficou evidente no material analisado, a julgar pela ênfase no uso de cientistas e profissionais da saúde como fontes de informação às reportagens, nas quais muitas vezes verifica-se uma personificação (Ordaz \& Vala, 1997; Vala \& Castro, 2013) do conhecimento, objetificado nas imagens desses profissionais. Joffe e Staerklé (2007) salientam que conhecimento sobre a competência científica é cada vez mais marcante nas mídias de massa, que usam os cientistas especialistas no assunto para objetificar o conhecimento ao público. Eles seriam os "guardiões da verdade" contra as posições e percepções emocionais e irracionais, tais como as vividas em superstições, misticismo e religião. $\mathrm{Na}$ revista Veja tem-se como exemplo o médico endocrinologista Alfredo Halpern, referenciado em grande parte das reportagens e uma das figuras presentes como porta-voz do desenvolvimento científico em relação às práticas de emagrecimento. Além disso, a mescla de informações científicas e de profissionais especializados, que garantem a credibilidade às informações, com as opiniões de leigos e celebridades, tem papel de aproximar o conhecimento científico da experiência cotidiana dos leitores, via processos de identificação social (Tajfel, 1969).

O conteúdo das reportagens foi acompanhado por imagens com baixa ocorrência de idosos, adolescentes e negros; refletindo um padrão social, cujo corpo ideal é magro, jovem e branco (Goetz, Camargo, Bertoldo \& Justo, 2008). O padrão estético das imagens exibe o corpo branco europeu, o que, em um país de grande variabilidade étnica e cultural como o Brasil, expressa o preconceito racial (Vala \& Lima, 2004), com poucas modificações ao longo de quatro décadas. E por mais que o envelhecimento populacional componha o cenário demográfico nessas últimas décadas (IBGE, 2017), ele também não está presente nas imagens publicadas.

A referência às ilustrações convida à reflexão sobre a dimensão imagética da RS, já que "as imagens têm o papel de anteparo seletivo que serve para receber novas mensagens e comandam frequentemente a sua percepção e a interpretação" (Moscovici, 2012, p. 45). No que se refere à imagem veiculada nas reportagens, a mesma é associada a adultos de cor branca, não necessariamente 
acima do peso, e diretamente vinculada às práticas de emagrecimento, em especial o controle alimentar.

No que diz respeito às imagens de capa, sobressaem-se ainda mais os corpos femininos, jovens, brancos e magros, condizentes como o padrão estético vigente. Mól e Pires (2006) sugerem que tais contornos corporais teriam a função de atestar a boa condição de saúde e sucesso daqueles que se submetem às prescrições do discurso midiático. Tamanho é o destaque da forma corporal que muitas vezes os rostos das modelos não aparecem, sendo exposto apenas o seu corpo, em trajes de praia. Com relação à imagem feminina verifica-se uma espécie de cristalização dos estereótipos de gênero, que ao longo do amplo período analisado pouco se modificam e não retratam as mudanças sociais vividas no país e no mundo nas últimas décadas.

Embora tenha sido constatado um importante crescimento no volume de material publicado ao longo do período pesquisado, as temáticas dos artigos apresentaram relativa estabilidade. O excesso de peso é necessariamente associado a ações que visam revertê-lo, a gordura precisa ser combatida e as reportagens trazem descobertas científicas que corroboram com esta norma social. Tais RS difundidas nas reportagens confirmam o pensamento encontrado por Piedras (2012), de que o corpo com sobrepeso é representado na maior parte das vezes como algo temporário e circunstancial, com possibilidade de ser corrigido, bastando para isso força de vontade das pessoas. Tal crença de que o excesso de peso é um estado passageiro contraria os dados epidemiológicos que revelam grandes insucessos relativos ao emagrecimento (Brasil, 2012). Conforme a OMS (2003), 95\% dos obesos fracassam na manutenção do seu programa de emagrecimento e voltam a engordar, evidenciando que o sobrepeso e a obesidade não seriam tão "reversíveis" quanto apontam as manchetes midiáticas.

As pessoas acima do peso raramente são destaque nas reportagens, a não ser quando se trata do seu sucesso ou fracasso em emagrecer - a exemplo da reportagem de outubro de 2012 que revela o processo de emagrecimento do ex-jogador de futebol Ronaldo, amplamente divulgado pela mídia do país na época. O fenômeno social - excesso de peso da população, assim como a vivência das pessoas nessa condição é quase que negado e o espaço midiático é ocupado pelas propostas cientificamente comprovadas de combate aos quilos a mais.

A experiência corporal abordada prioriza um modelo corporal a ser seguido em termos de aparência e saúde. Nesse sentido, o excesso de peso é invariavelmente abordado a partir de um ideal associado à magreza, como se a maior parte das pessoas pudessem atingir esse padrão por meio da adesão voluntária aos comportamentos específicos citados. Reitera-se que as notícias sobre o excesso de 
peso inserem-se majoritariamente num discurso associado à saúde que é invariavelmente ligada a comportamentos individuais, sendo tradicionalmente esta a atribuição causal mais comum nos discursos sociais de acordo com Adam e Herzlich (2001).

A alimentação regrada por meio de dietas restritivas mostra-se como a principal prática de controle de peso - especialmente nas reportagens a partir do ano 2000. O ato de comer é associado exclusivamente à função de nutrição corporal. Trata-se de um comer que é "medicalizado" e os alimentos são tratados de acordo com suas propriedades bioquímicas. Sabe-se que o comportamento alimentar envolve um agrupamento de fatores fisiológicos, emocionais, simbólicos e socioculturais (Quaioti \& Almeida, 2006). Aspectos sensoriais, culturais e até mesmo ritualísticos são intrínsecos à prática alimentar (Lahlou, 1995). Contudo, estes aspectos pouco foram mencionados nas inúmeras reportagens sobre 0 comportamento alimentar publicadas pela revista Veja, onde o alimento é encarado como uma espécie de "combustível" às funções metabólicas, com prevalência de informações essencialmente técnicas e prescritivas.

$\mathrm{Na}$ grande maioria das reportagens, o excesso de peso corporal é abordado como um potencial risco à saúde. Entretanto, enquanto fala-se exaustivamente nas práticas alimentares consideradas saudáveis, pouco é mencionado a respeito da prática regular de exercícios físicos, fator determinante para saúde e qualidade de vida, gerando efeitos protetores das doenças crônicas não transmissíveis associadas à obesidade (Macedo et. al, 2003).

Mas por que, ao considerar os riscos da obesidade à saúde, algumas práticas são priorizadas em detrimento de outras? Ao abordar o risco como um fenômeno psicossocial, não se pode deixar de atentar, conforme apontam Bousfield e Bertoldo (no prelo), aos processos sociocognitivos que fazem com que as pessoas pensem de uma determinada forma em relação a um determinado risco. Tais processos envolvem RS e uma elaboração coletiva do objeto social, que se dá em determinada cultura e faz parte de sua memória coletiva. Assim, a saliência dos riscos do excesso de peso para a saúde remete à representação de saúde que está em questão.

A respeito dos fatores normativos presentes em tal representação, reforça-se que as normas de saúde e beleza se sobrepõem e ambas são associadas ao emagrecimento, o que vem a corroborar com constatações de estudos anteriores. Afirmam Mól e Pires (2006) que é uma característica da mídia de massa abordar o corpo a partir de narrativas que o tratam com certa ambiguidade em relação à saúde e estética. Os autores mencionam a inexistência de fronteiras entre o corpo que é considerado belo e aquele considerado saudável. A aproximação de significados entre os termos saúde e estética na mídia pode estar associada ao fato que mesmo mensagens relativas à 
beleza se fundamentam no universo da saúde, uma vez que este, por se apoiar no discurso médico-científico, teria maior legitimidade (Mól $\&$ Pires, 2006).

Para Teo (2010), a saúde é percebida também como beleza física e o conceito de boa forma está mais atrelado à beleza do que propriamente à saúde, conquistada por uma alimentação saudável e prática de exercícios regulares. Alcançar o padrão é resultado de disciplina, esforço pessoal e poder econômico; deixando manifesta a responsabilização do sujeito por seu sucesso ou fracasso em emagrecer.

O corpo humano, elemento de uma experiência pessoal imediata, é também um objeto social, de expressão e interação e componente de um pensamento social regido por sistemas prescritivos, evidenciadas nas cenas sociais (Jodelet, 1994). Nesse âmbito verificou-se a prevalência de um corpo objeto, instrumento e até mesmo medicalizado, em detrimento das dimensões que refletem um corpo vivido, experienciado. A espontaneidade corporal é deixada de lado sendo praticamente inexistente a menção às experiências lúdicas e ou prazerosas ligadas ao corpo. A necessidade de controle do corpo e manutenção da magreza são enfatizadas, normas estas que se ancoram no discurso da saúde, legitimado pela ciência e confirmado por personalidades célebres na mídia brasileira.

Wagner (1998) aponta para a importância de se estudar a gênese das RS no contexto de comunicação, onde elas são constituídas e no contexto que elas nascem e se expressam. Nesse sentido, a exploração do conteúdo midiático contribui para a compreensão das RS acerca de temas relevantes ao cotidiano, a partir da identificação das temáticas que fazem parte dos discursos do senso comum, e da forma pela qual essas temáticas apresentam-se na "agenda" midiática. Nessa agenda pode-se observar que o excesso de peso é um tema em ascensão e necessariamente associado ao emagrecimento. A gordura precisa ser combatida e as reportagens trazem descobertas científicas que corroboram com esta norma social. O sobrepeso é tratado de forma negativa e as dificuldades enfrentadas pelas pessoas que o vivenciam ganham destaque. Não parece possível falar de sobrepeso na mídia sem mencionar o emagrecimento, o qual se mostra necessário e exige uma rotina regrada, muitas vezes na contramão das atividades sociais prazerosas.

Uma grande parte das informações que circulam no dia-a-dia têm a imprensa com fonte (Kasperson et al., 1988). Assim, ao identificar representações presentes em um importante veículo de difusão midiática brasileira, pode-se obter um panorama das crenças e atitudes e normas sociais relativas ao excesso de peso que circulam na sociedade. Num processo de difusão que é típico da imprensa generalista (Moscovici, 2012), a mídia tem o poder de reforçar e 
disseminar as normas descritivas (Thogersen, 2006) que estipulam o comportamento considerado "normal" em uma sociedade, consolidando padrões nos quais os indivíduos tendem a se ancorar, em menor ou maior grau suas comparações sociais.

\section{Considerações finais}

Ao analisar as publicações da revista Veja nas últimas quatro décadas, constatou-se que o aumento do número de publicações sobre o tema acompanha o crescimento do número de pessoas com excesso de peso no país. Ao mesmo tempo em que esse fenômeno afetou mais a população, ele também se mostrou mais evidente na mídia. As políticas de saúde relativas ao excesso de peso da população ascenderam em ritmo análogo, sendo desenvolvidas a partir de 1990 e ganhando destaque a partir do ano 2000 (Souza, 2010).

Embora tenha ganhado maior espaço na revista nos últimos anos, com ênfases que se modificaram, passando da atenção à obesidade como um objeto da ciência a um assunto do cotidiano, vivido por celebridades e pessoas comuns, a forma de abordar o corpo com excesso de peso mostra-se relativamente estável desde a década de 1960. A difusão de informações mescla ciência e senso comum de forma bastante pragmática. $\mathrm{E}$ as imagens veiculadas carregam estereótipos etários, de gênero e etnia que não acompanham as mudanças sociais vividas ao longo das últimas décadas.

As pessoas com excesso de peso são raramente o destaque e a ênfase é dada o emagrecimento, de modo que as representações ligadas à obesidade consideram-na um desvio da normalidade e associam-na diretamente a ações que visam revertê-la, invariavelmente no âmbito individual. Essas práticas são sustentadas por um discurso técnico-científico, legitimado por pesquisadores e profissionais da saúde que ressaltam os prejuízos do excesso de peso à saúde e revelam formas eficazes e cada vez mais modernas para perder peso. Ou seja, o corpo trata-se aqui de um objeto físico, alvo de intervenções que possibilitam entrar nos padrões de normalidade que são legitimados pela ciência.

Não se pode deixar de mencionar que um dos limites deste estudo refere-se à fonte utilizada, que se restringiu à revista Veja. Embora se saiba que os temas debatidos na agenda social sejam convergentes nos diversos meios de comunicação, não se pode deixar de considerar que há o risco da parcialidade nos dados encontrados. Nesse sentido, salienta-se a importância de expandir a pesquisa de mídia a outras fontes de dados, inclusive internet, que tem sido fonte importante de divulgação de informações, especialmente na última década. 


\section{Referências}

Adam, P., \& Herzlich, C. (2001). Sociologia da Doença e da Medicina. Bauru: EDUSC.

Alferes, V. R. (1987). O corpo: Regularidades discursivas, representações e patologias. Revista Crítica de Ciências Sociais, 23, 211-219.

Apostolidis, T. (2006). Contexte social et rapport à la santé: une contribution psychosociale. HDR, Aix-Marseille Université.

Andrieu, B. (2006). Corps. In B. Andrieu (Org.), Le dictionnaire du corps en sciences humaines e sociales (pp. 103-104). Paris: CNRS Editions.

Arruda, B. K. G., \& Arruda, I. K. G. (2007) Marcos referenciais da trajetória das políticas de alimentação e nutrição no Brasil. Revista Brasileira Saúde Matern. Infantil, 7(3), 319-326.

Banks, M. (2008). Dados Visuais: para pesquisa qualitativa. Porto Alegre: Artmed.

Bardin, L. (2009). Análise de Conteúdo: edição revista e actualizada. Lisboa: Edições 70.

Berger, P. L. \& Luckmann, T. (2011). A construção social da realidade. Petrópolis: Vozes.

Bousfield, A. B. S., \& Bertoldo, R. (no prelo). Riscos coletivos: Um olhar psicossocial. In A. O. Silva \& B. V. Camargo (Eds.), Representações sociais do envelhecimento e da saúde. João Pessoa: Editora Universitária da UFPB.

Brasil. Ministério da Saúde (2011). Portaria no 719, de 07 de abril de 2011. Instituto Programa Academia da Saúde no âmbito do Sistema Único de Saúde. Disponível em: http: //portal.saude.gov.br/portal/arquivos/pdf/portaria_academ ia_saude_719.pdf

Brasil. Ministério da Saúde (2012). Quase metade da população brasileira está acima do peso. Portal da Saúde - publicado em 16/04/2012.

Camargo, B. V. (2003). A televisão como vetor de difusão de informações sobre a AIDS. In M. L. P. Coutinho, A. S. Lima, M. L. Fortunato, \& F. B. Oliveira (Org.), Representações sociais: Abordagem interdisciplinar (pp. 130-152). João Pessoa: Editora Universitária.

Camargo, B. V., \& Justo, A. M. (2013). IRAMUTEQ: Um software gratuito para análise de dados textuais. Temas em Psicologia, 21(2).

Chaves, A. M., \& Silva, P. L. (2011). Representações Sociais. In L. Camino, A. R., Torres, M. E. O. Lima, \& M. E. Pereira (Orgs.) Psicologia Social: Temas e Teorias (pp. 299-350). Brasília: Technopolitik. 
Dayan, D. (2003) Sociologie des médias: le détour par l'ethnographie. In S. Moscovici, \& F. Buschini (Orgs), Les Méthodes des sciences humaines (pp. 445-465). Paris: PUF.

Downs, A. (1972). Up and Down with Ecology-the Issue-Attention Cycle, Public Interest, 28, 38-50.

EGM, Estudos Marplan Consolidado (2012). Pesquisa público leitor. Disponível em: http://www.publiabril.com.br/marcas/veja/revista/informacoesgerais, acesso em 11/06/2013.

Fischer, G N. (1996). Os conceitos fundamentais da psicologia social. Lisboa: Instituto Piaget.

Fischer, G. N. (2002). Traité de psychologie de la santé. Paris: Dunod.

Goetz, E. R., Camargo, B. V., Bertoldo R. B., \& Justo, A. M. (2008). Representações sociais do corpo na mídia impressa. Psicologia e Sociedade, 20(2), 226-236.

Instituto Brasileiro de Geografia e Estatística - (2017). Popclock Projeção 2013. População. Disponível em: http://www.ibge.gov.br/apps/populacao/projecao/notatecnica.h tml acesso em 27/04/17.

Jodelet, D. (1984). Répresentation Sociale: phénomènes, concept et théorie. In S. Moscovici (Ed.), Psychologie sociale (pp. 363384). Paris: P.U.F.

Jodelet, D. (1994). Le corps, la persone et autrui. In S. Moscovici (Org.), Psychologie sociale des relations à autrui (pp. 41-68). Paris: Nathan.

Jodelet, D. (2001). Representações sociais: Um domínio em expansão (Trad.). In D. Jodelet (Org.), As representações sociais (pp. 187-203). Rio de Janeiro: Eduerj.

Jodelet, D. (2006). Place de l'expérience vécue dans les processus de formation des représentations socials. In V. Haas, (Dir.), Les savoirs du quotidian (pp. 235-255). Rennes: PUR.

Joffe, H., \& Staerklé, C. (2007). The centrality of the self-control ethos in western aspersions regarding outgroups: a social representational approach to stereotype content. Culture Psychology, 13(4), 395-418.

Justo, A. M. (2016). Corpo e representações sociais: sobrepeso, obesidade e práticas de controle de peso. Tese de Doutorado em Psicologia. Programa de Pós-Graduação em Psicologia. Universidade Federal de Santa Catarina. Florianópolis (SC).

Kasperson, R., Renn, O., Slovic, P., Brown, H. and Emel, J. (1988). Social Amplification of Risk: a Conceptual framework. Risk Analysis, 8(2), 177-187.

Kientz, A. (1973). Comunicação de massa: análise de conteúdo. Rio de Janeiro: Eldorado. 
Lahlou, S. (1995) Les représentations du bien manger. In N. François $\&$ V. Egizio (Eds.), Agro-alimentaire: une économie de la qualité (51-64). Paris: Inra / Economica.

Macedo, C. S. G., Garavello, J. J., Oku, E. C., Miyagusuku, F. H., Dall Agnol, P., \& Nocetti, P. M. (2003). Benefícios do exercício físico para a qualidade de vida. Revista Brasileira de Atividade Física: Saúde, 8(2), 19-27.

Marková, I. (2006). Dialogicidade e representações sociais: as dinâmicas da mente. Petrópolis: Vozes.

Mól, M. C., \& Pires, G. L. (2006). Feliz na contemporaneidade: saúde e estética no discurso de Veja. Corpoconsciência, 10(1), 23-38.

Morin, M., \& Apostolidis, T. (2002). Contexte social et santé. In G. Fischer (Org.), Traité de psychologie de la santé (pp. 463-489). Paris: Dunod.

Moscovici, S. (1981) On social representation In J. P. Forgas (Org.) Social cognition: Perspectives on everyday understanding. London: Academic Press.

Moscovici, S. (1984) Introduction: le domaine de la psychologie sociale. In S. Moscovici (Ed.), Psychologie sociale (pp. 5-22). Paris, P.U.F.

Moscovici, S. (2012). A psicanálise: sua imagem, seu público. Porto Alegre: Vozes.

Ordaz, O., \& Vala, J. (1997). Objectivação e ancoragem das representações sociais do suicídio na imprensa escrita. Análise Social, 32, 143-144.

Organização Mundial da Saúde - OMS (2015). Obesity and overweight. WHO Media centre, fact sheet V. 311. Disponível em: http://www.who.int/mediacentre/factsheets/fs311/en/ acesso em 28/12/2015.

Organização Mundial da Saúde - OMS. (2003) Diet, nutrition and the prevention of chronic diseases. Report of a joint WHO/FAO expert consultation. WHO Technical Report Series 916. Geneva.

Piedras, G. C.(2012). La experiencia subjetiva del cuerpo con sobrepeso. Sociológica, 27(75), 125-155.

Quaioti, T. C. B., \& Almeida, S. S. (2006). Determinantes psicobiológicos do comportamento alimentar: uma ênfase em fatores ambientais que contribuem para a obesidade. Psicologia USP, 17(4), 193-211.

Rouquette, M. L. (1986). La comunicación de masas. In S. Moscovici (Coord.). Psicología Social II: Pensamiento y vida social; Psicología social y problemas sociales (pp. 627-647), Buenos Aires: Paidós.

Rouquette, M. L. (2005). As representações sociais no quadro geral do pensamento social. In A. S. P. Moreira, B. V. Camargo, J. C. Jesuíno, \& S. M. Nóbrega (Eds.) Perspectivas teórico- 
metodológicas em representações sociais (p. 189-200). João Pessoa: UFBP Editora Universitária.

Rüdiger, F. (2011). As teorias da comunicação. Porto Alegre: Penso.

Separavich, M. A., \& Canesqui, A. M. (2010). Girando a Lente Socioantropológica sobre o Corpo: uma breve reflexão. Saúde Sociedade, 19(2), 249-259.

Shaw, E. F. (1979). Agenda-Setting and Mass Communication Theory. International Communication Gazette, 25, 96-105.

Silva, R. D. O., \& Gonzales, L. S. (2008). Jornalismo, publicidade e capas da revista Veja: Uma relação de Interpendência. In Anais do I Simpósio de Comunicação e Tecnologias Interativas (pp. 418-433).

Souza, E. D. (2010). Transição nutricional no Brasil: análise dos principais fatores. Cadernos UniFOA, 13, 49-53.

Tajfel, H. (1969). Cognitive aspects of prejudice. Journal of Social Issues, 25, 79-97.

Teo, C. R. P. A. (2010). Discursos e a Construção do Senso Comum sobre Alimentação a Partir de uma Revista Feminina. Saúde e Sociedade, 19(2), 333-346.

Thogersen, J. (2006). Norms for environmentally responsible behaviour: An extended taxonomy. Journal of Environmental Psychology, 26, 247-61.

Vala, J., \& Castro, P. (2013). Pensamento social e representações sociais. In J. Vala \& M. B. Monteiro (Coord.), Psicologia social (pp. 569-602). Lisboa: Fundação Calouste Gulbenkian.

Vala, J., \& Lima, M. E. O. (2004). As novas formas de expressão do preconceito e do racismo. Estudos de Psicologia, 9(3), 401-411.

Veloz, M. C. T., Nascimento-Schulze, C. M., \& Camargo, B. V. (1999). Representações sociais do envelhecimento. Psicologia: Reflexão e Crítica, 12(2), 479-501.

Villalta, D. (2002). O surgimento da revista Veja no contexto da modernização brasileira. In Anais do XXV Congresso Brasileiro de Ciências da Comunicação - Salvador/BA - 1 a 5 Set 2002. Inercom: Sociedade Brasileira de Estudos Interdisciplinares da Comunicação.

Wolf, M. (1999). Teorias da Comunicação. Lisboa: Presença.

Wagner, W. (1998). Sócio-gênese e características das representações sociais. In A. S. P. Moreira \& D. C. de Oliveira (Orgs.), Estudos interdisciplinares de representação social (pp. 3-25). Goiânia: AB. 


\section{Endereço para correspondência}

\section{Ana Maria J usto}

Universidade Federal do Espírito Santo - UFES

Programa de Pós-Graduação em Psicologia

Av. Fernando Ferrari, 514, Goiabeiras, CEP 29075-910, Vitória - ES, Brasil

Endereço eletrônico: anamjusto@yahoo.com.br

\section{Brigido Vizeu Camargo}

Universidade Federal de Santa Catarina - UFSC

Departamento de Psicologia

Campus Universitário Trindade, Bloco C - 2o piso, CEP 88040-900, Florianópolis SC, Brasil

Endereço eletrônico: brigido.camargo@yahoo.com.br

Recebido em: 14/08/2015

Reformulado em: 27/04/2017

Aceito em: 30/04/2017

\section{Notas}

* Doutora em Psicologia pela Universidade Federal de Santa Catarina e Professora Adjunta do Departamento de Psicologia Social e do Desenvolvimento da Universidade Federal do Espírito Santo.

** Doutor em Psicologia Social pela École des Hautes Études en Sciences Sociales e Professor Titular do Departamento de Psicologia da Universidade Federal de Santa Catarina.

\section{Agradecimentos}

Agradecemos à CAPES pela concessão de bolsa de doutorado à primeira autora.

Este artigo de revista Estudos e Pesquisas em Psicologia é licenciado sob uma Licença Creative Commons Atribuição-Não Comercial 3.0 Não Adaptada. 